\title{
Thoracic myelopathy secondary to multi-level ossification of the ligamentum flavum in an Asian patient
}

\author{
Chiara J Chong*, Wan Tin Lim \\ Department of Internal Medicine, Singapore General Hospital, Singapore
}

Received: February 12, 2017

DOI: $10.5430 /$ crim.v4n3p46

\author{
Accepted: June 28, 2017 \\ Online Published: July 16, 2017 \\ URL: https://doi.org/10.5430/crim.v4n3p46
}

\begin{abstract}
Thoracic myelopathy occurs less frequently than lumbar myelopathy. There are several causes of thoracic myelopathy of which ossification of the ligamentum flavum (OLF) is one. OLF has several unique features, arising posteriorly and causing proprioceptive issues first before extending to cause motor and sensory loss. We present a case of a 58-year-old gentleman with a six-month history of progressive lower limb weakness, numbness, back pain and recurrent falls due to OLF. Magnetic resonance and computed tomography imaging revealed extensive thoracic OLF and concomitant facet hypertrophy involving T6-7, T7-8, T9-10, T10-11 and L1-2. Severe central canal stenosis and L1-2 cauda equina root compression were also seen on radiological imaging. The patient developed sphincter disturbance during his admission and had difficulty passing urine. He underwent physiotherapy but was only able to sit and stand with the help of a walking frame at best. He did not regain motor or sensory function in his lower limbs although his back pain improved. Surgical decompression is associated with good neurological outcomes in OLF. Despite this, our patient declined surgery and opted for conservative therapy instead. We wish to highlight a rare case of thoracic myelopathy and the potentially irreversible neurological deterioration that occurs if there is no early surgical intervention.
\end{abstract}

Key Words: Ossification of ligamentum flavum, Thoracic myelopathy

\section{INTRODUCTION}

Thoracic myelopathy occurs less frequently than lumbar myelopathy. There are several causes of thoracic myelopathy such as ossification of the ligamentum flavum (OLF) and ossification of the posterior longitudinal ligament (OPLL). OLF has gained increasing recognition due to advances in radiological imaging. It can present in two distinct patterns - either as a progressive myelopathy over months causing gait imbalance before the onset of spastic paraparesis, or less commonly as an acute spinal cord injury occurring after back trauma in an asymptomatic patient with pre-existing OLF. ${ }^{[1]}$ OLF can lead to irreversible spinal cord compression and paraplegia if not treated early with surgery. Our patient presented with a classical history of progressive myelopathy due to OLF and experienced complications of spinal cord compression. He declined surgery despite extensive neurological involvement. We would like to highlight this rare case of thoracic myelopathy to guide physicians in their management of similar cases, while stressing the benefits of early surgery as the duration of symptoms prior to surgery is

\footnotetext{
*Correspondence: Chiara J Chong; Email: chiara.chong.j.m@ singhealth.com.sg; Address: Department of Internal Medicine, Singapore General Hospital, Academia Level 4, 20 College Road, 169856, Singapore.
} 
highly determinant of surgical outcomes. ${ }^{[2,3]}$ Conservative therapy is not known to be effective. ${ }^{[4]}$

\section{Case presentation}

A 58-year-old gentleman presented with lower back pain of five to six months' duration. He took paracetamol with minimal improvement. This was associated with bilateral lower limb weakness and numbness for one month. He had difficulty walking and could only walk very short distances with assistance. He progressively became chair-bound. $\mathrm{He}$ also reported multiple falls of at least seven to eight times due to his lower limb weakness. He did not sustain any injury to his back. He did not have any urinary or bowel incontinence on presentation to the hospital.

He had no relevant medical history. He was well and fully ambulant prior to the onset of pain six months ago.

Neurological examination revealed an upper motor neuron pattern of weakness in his lower limbs. He had increased tone, power of grade 3 on the Medical Research Council
(MRC) scale, hyperreflexia, and reduced sensation to pin prick. He was not able to perform the heel-shin test and proprioception in the big toe was lost. Examination of the upper limbs showed normal tone and reflexes, and power of grade 4 on the MRC scale. There was normal peri-anal sensation and anal tone. Examination of other systems were unremarkable.

\subsection{Investigations}

Hematological and biochemistry investigations were normal. Cervical spine radiograph showed OPLL at C2-4 levels and mild spondylosis. Lumbar spine radiographs showed mild spondylotic changes.

Computed tomography (CT) of the thoracic spine showed extensive tuberous type ossification of the ligamentum flavum involving T6/7, T7/8, T9/10 and T10/11 (see Figure 1A). Ossification occurred bilaterally and was worse on the left. There was also severe central canal and lateral recess stenosis at these levels.

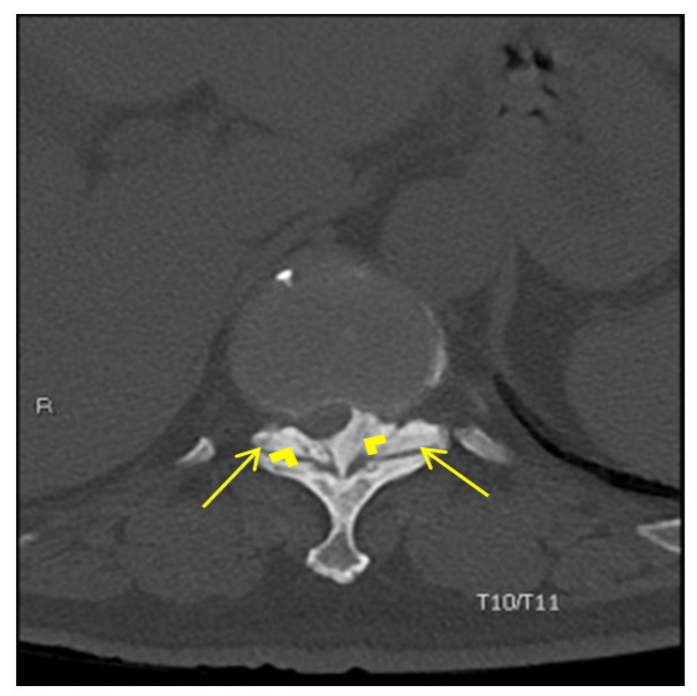

A

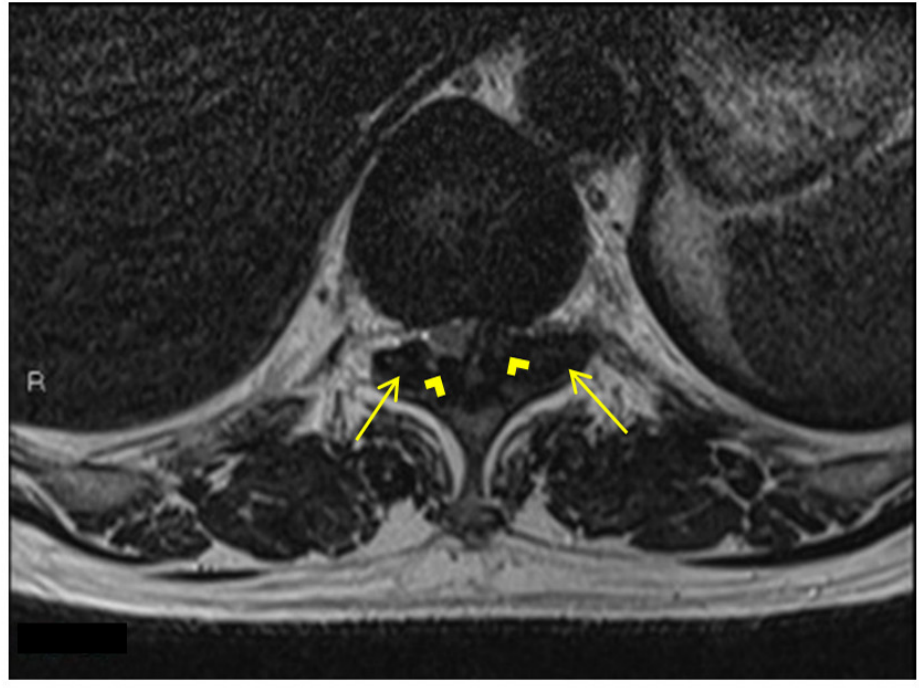

B

Figure 1. A) Ossification of ligamentum flavum (arrow heads) and facet joint hypertrophy (long arrows) on CT (T10/11). B) MRI thoracic spine (T10/11) showing bilateral flavum and facet hypertrophy, severe central canal stenosis

Magnetic resonance imaging (MRI) of the patient's spine was also performed. Ossification and severe central canal stenosis was once again seen on the same levels as CT thoracic-spine and at L1/2. In addition, bilateral thoracic facet hypertrophy and cord compression at T6, T7/8, T10/11 were seen. Hyperintensity was also seen on T2 imaging at T6/7 and T7/8 levels to suggest myelopathy. At the level of T10/11, left sided predominant flavum and facet hypertrophy caused severe central canal stenosis and resultant distortion of the cord, as well as subtotal effacement of the cerebrospinal fluid (CSF) space (see Figure 1B).

At L1/2, prominent focal paramedian protrusion caused severe central canal stenosis with effacement of the CSF space. There was also concomitant bilateral recess and exit canal stenosis, resulting in bunching of the cauda equina roots immediately above the level and cauda equina compromise (see Figure 2). 
A transcranial magnetic stimulation study was also done which showed absent motor evoked potentials (MEP) in the lower limbs and reduced MEP amplitudes in the upper limbs, consistent with corticospinal tract dysfunction at the level of the spinal cord.

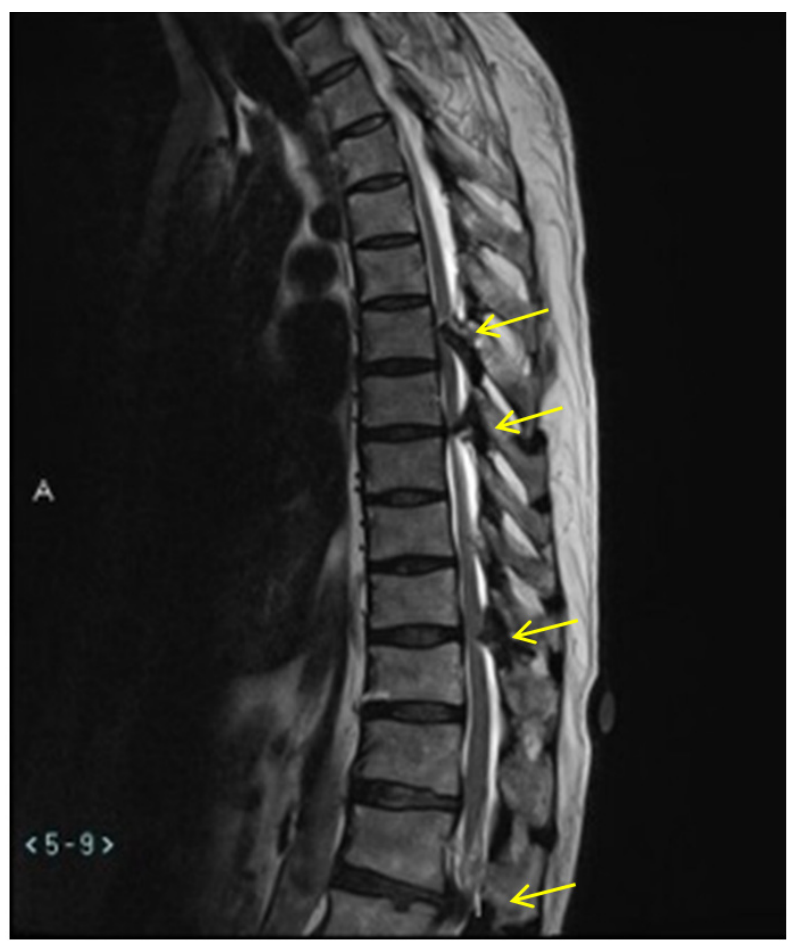

Figure 2. MRI thoracic spine (sagittal view) showing cord compression at T6, T7/8, T10/11, L1/2 (long arrows)

\subsection{Treatment}

Our patient was offered surgical decompression with the option of spinal instrumentation. However, he declined surgical intervention despite full knowledge that his neurological prognosis would be poor with conservative treatment only.

He underwent regular physiotherapy sessions and managed to achieve good sitting and moderate standing balance. However, he never regained the ability to walk. His back pain improved with paracetamol and he eventually did not require any analgesia. He also received oral dexamethasone $4 \mathrm{mg}$ three times a day and his dose was tapered every three days.

\subsection{Outcome and follow-up}

Our patient developed acute retention of urine during his admission. This was not surprising as cauda equina compromise at L1/2 had been seen earlier on MRI imaging. He declined urinary catheter insertion and was placed on strict scheduled voiding. He was able to void satisfactorily and achieved post-voiding residual urine volumes from 0 to $200 \mathrm{ml}$. His motor function was as above and his sensory loss did not improve. He was later transferred to a step-down facility for further rehabilitation. At two months post-discharge, his neurological function remains poor.

\section{Discussion}

OLF was first diagnosed by Polgar in 1920 and was traditionally viewed as a disease affecting East Asians with a predominance among Japanese. ${ }^{[5]}$ However, recent case series and reports have also been published from North and South America, Africa, Middle East, India and Europe. ${ }^{[6]}$ The higher prevalence among Japanese is thought to be attributed to the traditional custom of kneeling and standing, which causes increased mechanical stress on the thoracic spine. ${ }^{[7]}$ Fujimori et al. reported a $12 \%$ prevalence of thoracic OLF in healthy Japanese subjects undergoing screening positron emission tomography-computed tomography (PET-CT). ${ }^{[8]}$

The pathophysiology of OLF remains unclear. Mechanical stress on the ligamentum flavum is thought to accelerate endochondral ossification. ${ }^{[9]}$ Inflammatory cytokines such as IL-6 and TNF- $\alpha$ have also been shown to be involved. ${ }^{[9]}$ The lower thoracic spine is most commonly affected as it is thought to be subjected to the most tensile force. ${ }^{[7]}$ In order of frequency, thoracic segments most commonly involved are: T10/11, T9/10, and T11/12. ${ }^{[10]}$ Ossification can affect several levels and occur in a contiguous or non-contiguous fashion. ${ }^{[11]}$ OLF frequently co-exists with OPLL, ossification of the dura and cervical/lumbar spondylosis. ${ }^{[11,12]}$ This may contribute to a delay in diagnosis and complicate management.

\subsection{Clinical presentation}

OLF can present either as a subacute progressive myelopathy over months, or as an acute spinal cord injury post trauma in a patient with pre-existing asymptomatic disease. The latter presentation is associated with poorer outcomes. ${ }^{[13]}$ Interestingly, as OLF progresses in a posterior to anteriormedial fashion, the dorsal columns are affected before the corticospinal and spinothalamic tracts. ${ }^{[7]}$ This gives rise to balance and co-ordination problems before the onset of motor weakness and numbness.

Our patient had a six-month history of back pain, lower limb weakness and numbness, recurrent falls and urinary retention. These are consistent with the findings of Kang et al. ${ }^{[14]}$ which found that $80 \%$ of patients presented with motor involvement, $67 \%$ with sensory deficit, and $59 \%$ with pain, numbness or claudication. Patients' symptoms should be scored on the modified Japanese Orthopedic Association (JOA) score (see Table 1) to assess the severity of myelopathy. The JOA score varies from 0 to 11 , with a smaller number signifying poorer neurological function. Our patient's JOA score was 3. 
Table 1. Modified Japanese orthopedic association score for thoracic myelopathy

\begin{tabular}{ll}
\hline Neurological status & Points \\
\hline Lower limb motor dysfunction & 0 \\
Unable to walk & 1 \\
Able to walk on flat floor with walking aid & 2 \\
Able to walk up and/or down stairs with handrail & 3 \\
Lack of stability and smooth reciprocation of gait & 3 \\
Normal & 4 \\
Lower limb sensory dysfunction & 0 \\
Severe sensory loss or pain & 1 \\
Mild sensory loss & 2 \\
Normal & \\
Truncal sensory dysfunction & 0 \\
Severe sensory loss or pain & 1 \\
Mild sensory loss & 2 \\
Normal & \\
Sphincter dysfunction & 0 \\
Unable to void & 1 \\
Marked difficulty in micturition & 2 \\
Mild difficulty in micturition & 3 \\
Normal & \\
\hline
\end{tabular}

\subsection{Radiological imaging}

Combination CT and MRI imaging are advocated. CT helps to diagnose OLF, while MRI allows closer examination of the cord to confirm the longitudinal extent of OLF and screen for concomitant spinal pathologies. ${ }^{[13]}$ OLF can also be classified based on its radiological features on sagittal and axial sequences. Appearance on sagittal cuts can be classified into beak or round type OLF. Appearance on axial cuts are classified using the Sato classification which divides lesions into lateral, extended, enlarged, fused or tuberous types. ${ }^{[7]}$ In the case of our patient, MRI was helpful to elucidate concomitant facet hypertrophy and cord compression at multiple levels (T5, T6/7 and T9/10).

\subsection{Surgery}

Surgical intervention has been said to be the only treatment for OLF as conservative therapy portends a poor response. ${ }^{[15]}$
Good prognostic factors include a JOA score $>6$, beak type OLF on MRI (versus round type), and shorter pre-operative duration of symptoms. ${ }^{[10,14,16]}$ Factors such as age, gender, level of ossified lesion, number of affected segments, co-existing OPLL had no impact on surgical outcomes. ${ }^{[17]}$ Despite becoming chair-bound and experiencing sphincter dysfunction, our patient was not keen for surgery. His duration of symptoms, low pre-operative JOA score, and cord involvement at multiple levels suggest a poor neurological prognosis that is unlikely to improve without surgery.

Surgical decompression offers patients good neurological recovery. Methods of decompression include laminotomy, laminoplasty, laminectomy and dural excision with or without patch graft, and laminectomy with floating ossified dura mater. ${ }^{[7]}$ Staged surgery for multi-segment OLF has also been showed to have good outcomes. ${ }^{[18]}$ Varying improvement of pre- and post-operative JOA scores have been reported, ranging from 5.6 pre-operatively and 7.8 post-operatively, ${ }^{[15]}$ to 3.8 pre-operatively and 8.2 postoperatively. ${ }^{[19]}$ Recovery rate can be calculated using the JOA formula ${ }^{[14]}$ where:

Recovery rate $=[$ (post-operative JOA score - pre-operative JOA score $) /(11$ - pre-operative JOA score $)] \times 100$

The most common complications of surgery are dural tears and CSF leak, which may occur more frequently when dural ossification co-exists with OLF. Other complications include post-operative neurological deterioration, epidural hematoma, CSF pseudocyst, meningitis and wound infection. ${ }^{[19,20]}$

In conclusion, OLF is a common cause of thoracic myelopathy that can present as a progressive myelopathy or acutely in patients with back trauma. Both CT and MRI imaging are advised to examine the extent of disease. Surgical decompression is favored over conservative treatment. Pre-operative JOA score, duration of symptoms and beak type OLF on MRI are good prognostic factors. ${ }^{[10,14,16]}$

\section{Conflicts of InTERest Disclosure}

The authors have declared no conflicts of interest.

\section{REFERENCES}

[1] Li KK, Chung OM, Chang YP, et al. Myelopathy caused by ossification of ligamentum flavum. Spine. 2002 Jun 15; 27(12): E308-12. PMid:12065995 https : //doi.org/10.1097/00007632-20020 6150-00026

[2] He S, Hussain N, Li S, et al. Clinical and prognostic analysis of ossified ligamentum flavum in a Chinese population. J Neurosurg Spine. 2005 Nov; 3(5): 348-54. PMid:16302628 https: //doi.org/10.3171/spi.2005.3.5.0348

[3] Miyakoshi N, Shimada Y, Suzuki T, et al. Factors related to long-term outcome after decompressive surgery for ossification of the ligamentum flavum of the thoracic spine. J Neurosurg. 2003 Oct; 99(3 Suppl): 251-6. https://doi.org/10.3171/spi.2003.99.3.0251

[4] Yabe Y, Honda M, Hagiwara Y, et al. Thoracic radiculopathy caused by ossification of the ligamentum flavum. Ups J Med Sci. 2013 Mar; 118(1): 54-8. PMid:23163624 https ://doi.org/10.3109/0300 
9734.2012 .715598

[5] Sagar H, Fernandez-Madrid F, Kupsky W. Rare cause of thoracic myelopathy: ossified ligamentum flavum. J Clin Rheumatol. 2010 Oct; 16(7): 326-9. PMid:20859225 https : //doi.org/10.1097/ RHU.0b013e3181eeb94f

[6] Toledo JA, Isseldyk FV, Re M, et al. Ossification of the ligamentum flavum as cause of thoracic cord compression: Case report of a Latin American man and review of the literature. Surg Neurol Int. 2013; 4: 119. PMid:24083054 https://doi.org/10.4103/2152-780 6.118489

[7] Ahn DK, Lee S, Moon SH, et al. Ossification of the ligamentum flavum. Asian Spine J. 2014 Feb; 8(1): 89-96. PMid:24596612 https://doi.org/10.4184/asj.2014.8.1.89

[8] Fujimori T, Watabe T, Iwamoto Y, et al. Prevalence, Concomitance, and Distribution of Ossification of the Spinal Ligaments: Results of Whole Spine CT Scans in 1500 Japanese Patients. Spine. 2016 Nov 1; 41(21): 1668-76. PMid:27120057 https://doi.org/10.109 $7 /$ BRS . 0000000000001643

[9] Ren L, Hu H, Sun X, et al. The roles of inflammatory cytokines in the pathogenesis of ossification of ligamentum flavum. Am J Transl Res. 2013 Sep 25; 5(6): 582-5. PMid:24093055

[10] Gao R, Yuan W, Yang L, et al. Clinical features and surgical outcomes of patients with thoracic myelopathy caused by multilevel ossification of the ligamentum flavum. Spine J. 2013 Sep; 13(9): 1032-8. PMid:23541451 https://doi.org/10.1016/j.spinee .2013 .02 .034

[11] Feng F, Sun C, Chen Z. Progress on clinical characteristics and identification of location of thoracic ossification of the ligamentum flavum. Orthop Surg. 2015 May; 7(2): 87-96. PMid:26033987 https://doi.org/10.1111/os.12165

[12] Li B, Qiu G, Guo S, et al. Dural ossification associated with ossification of ligamentum flavum in the thoracic spine: a retrospective analysis. BMJ Open. 2016 Dec 20; 6(12): e013887. PMid:27998902 https ://doi.org/10.1136/bmjopen-2016-013887
[13] Li Z, Ren D, Zhao Y, et al. Clinical characteristics and surgical outcome of thoracic myelopathy caused by ossification of the ligamentum flavum: a retrospective analysis of 85 cases. Spinal Cord. 2016 Mar; 54(3): 188-96. PMid:26238315 https ://doi .org/10 $.1038 /$ sc. 2015.139

[14] Kang KC, Lee CS, Shin SK, et al. Ossification of the ligamentum flavum of the thoracic spine in the Korean population. J Neurosurg Spine. 2011 Apr; 14(4): 513-9. PMid:21275554 https: //doi.org/10.3171/2010.11.SPINE10405

[15] Ando K, Imagama S, Ito Z, et al. Progressive relapse of ligamentum flavum ossification following decompressive surgery. Asian Spine J. 2014 Dec; 8(6): 835-9. PMid:25558329 https ://doi .org/10.4 184/asj.2014.8.6.835

[16] Hur H, Lee JK, Lee JH, et al. Thoracic myelopathy caused by ossification of the ligamentum flavum. J Korean Neurosurg Soc. 2009 Sep; 46(3): 189-94. PMid:19844616 https://doi.org/10.334 0/jkns.2009.46.3.189

[17] Inamasu J, Guiot BH. A review of factors predictive of surgical outcome for ossification of the ligamentum flavum of the thoracic spine. J Neurosurg Spine. 2006 Aug; 5(2): 133-9. PMid:16925079 https://doi.org/10.3171/spi.2006.5.2.133

[18] Li W, Guo S, Sun Z, et al. Multilevel thoracic ossification of ligamentum flavum coexisted with/without lumbar spinal stenosis: staged surgical strategy and clinical outcomes. BMC Musculoskelet Disord. 2015 Aug 19; 16: 206. PMid:26286579 https: //doi.org/10.1186/s12891-015-0672-5

[19] Zhong ZM, Wu Q, Meng TT, et al. Clinical outcomes after decompressive laminectomy for symptomatic ossification of ligamentum flavum at the thoracic spine. J Clin Neurosci. 2016 Jun; 28: 77-81. PMid:26898582 https://doi.org/10.1016/j.jocn. 2015.09 .023

[20] Sun X, Sun C, Liu X, et al. The frequency and treatment of dural tears and cerebrospinal fluid leakage in 266 patients with thoracic myelopathy caused by ossification of the ligamentum flavum. Spine. 2012 May 20; 37(12): E702-7. PMid:22609726 https: //doi .org/10.1097/BRS.0b013e31824586a8 